VARIA 



\title{
FRAGMENTOS DE INSCRIPCIONES ÁRABES HALLADOS EN Puebla de Guzmán (Huelva)
}

\author{
Mª Antonia MartíneZ NúÑEZ \\ Universidad de Málaga \\ Juan Aurelio Pérez Macías \\ Universidad de Huelva
}

Recibido: 7/04/2014

Revisado: 30/04/2014

RESUMEN

En este trabajo se estudia el hallazgo de inscripciones árabes procedentes del lugar de $\mathrm{La}$ Peña del Águila (Puebla de Guzmán, Huelva), y se relacionan con otros epígrafes aparecidos anteriormente en este sitio. Esta epigrafía valida la ocupación almohade y confirma su identificación con el asentamiento de Alfajar da Penha/Alfayat de la Peña, que se registra en las crónicas de la conquista portuguesa y la posterior repoblación castellana de este sector.

Palabras Clave

al-Andalus; Epigrafía; Árabe; Necrópolis; Suroeste Ibérico; Almohades.
ABSTRAC

In this paper are studied the discovery of arabics inscriptions from the site of La Peña del Águila (Puebla de Guzmán, Huelva), and relate to other headings appearing in this site. This epigraphy fragments validates the Almohad occupation and confirms its identification with the settlement Alfajar da Penha/ Alfayat de la Peña, which is recorded in the chronicles of the portuguese conquest and subsequent castillan repopulation of this sector.

\section{KEYWORDS}

al-Andalus; Epigraphy; Arabic; Necropolis; SW Spain; Almohad. 

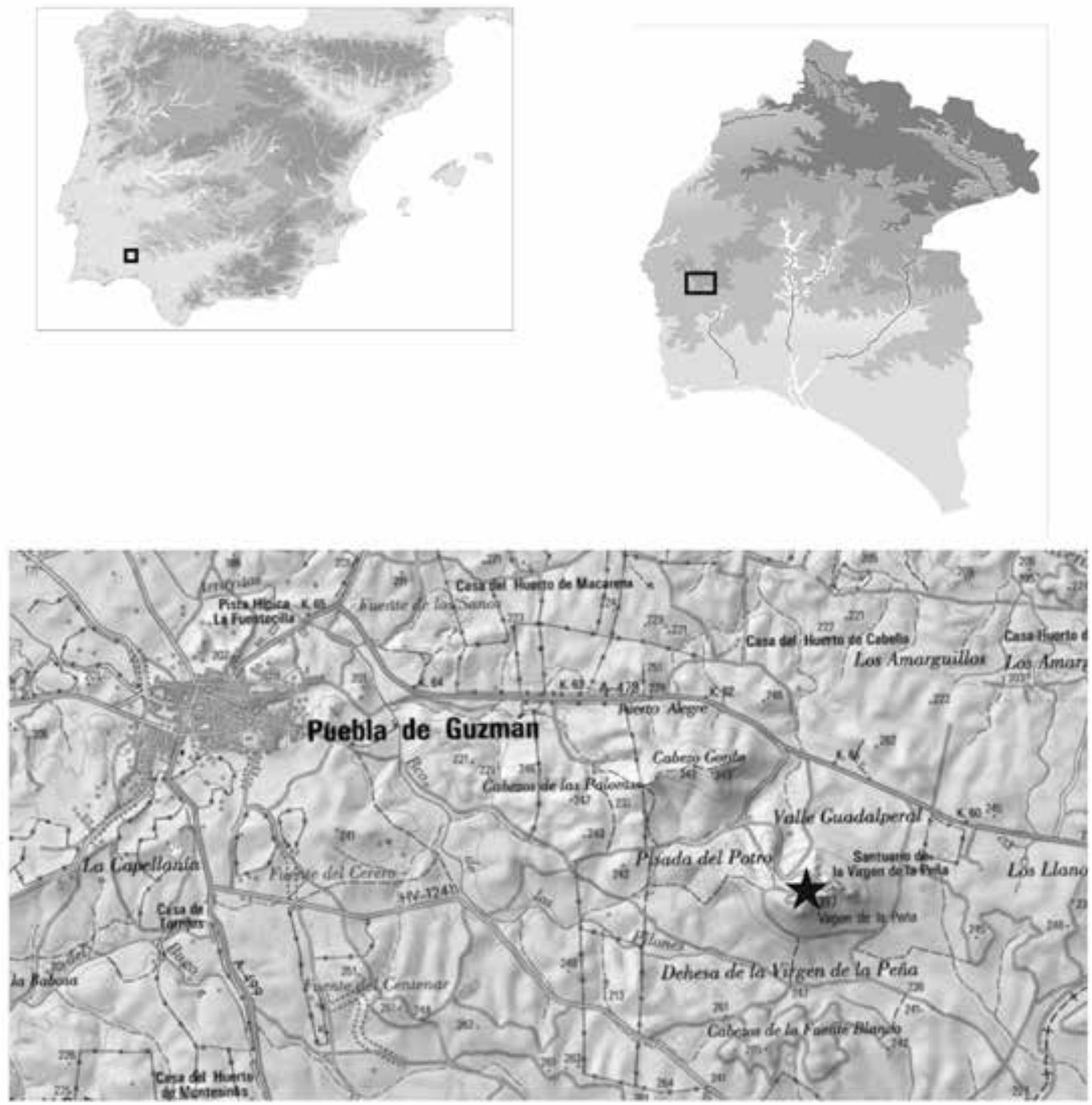

Fig. 1. Ubicación del hallazgo de los fragmentos epigráficos.

Son dos fragmentos de epígrafes árabes que fueron hallados en el año 2013, en uno de los muros conservados del Castillo del Águila, que se ubica en el lugar de La Peña del Águila en Puebla de Guzmán (Huelva), junto al Santuario de la Virgen de la Peña (figura 1), donde se encuentran los restos del despoblado medieval de Alfayat de la Peña.

Los dos fragmentos, que actualmente se conservan en manos de un vecino de Puebla de Guzmán, tienen unas características de material, talla y grafía muy similares, por lo que pueden muy bien pertenecer a una misma pieza.

Así, ambos fragmentos formarían parte de una estela funeraria de pizarra en cuyo frente se ha grabado el epitafio de un varón, en cúfico inciso. Esta técnica de talla y este mismo material se documentan en otros dos hallazgos epigráficos de Puebla de
Guzmán $^{1}$ y en inscripciones andalusíes de diversas procedencias, como las recientemente localizadas en la provincia de Badajoz ${ }^{2}$. La superficie de la pie-

1 R. Amador de los Ríos, Inscripciones árabes de Sevilla, Madrid, 1875, reed. Facsímil, Sevilla, 1998, ${ }^{\circ}$ IV, 108-110; D. Oliva, E. Gálvez y R. Valencia, "Fondos epigráficos del Museo Arqueológico de Sevilla", Al-Qantara, 6, 1 (1985), $n^{\circ} 3,455-456$. El hallazgo fue anterior a 1875, fecha en que publica su monografía Amador de los Ríos, y eran dos lápidas sepulcrales en pizarra, pero una de ellas tan deteriorada, según la descripción que se ofrece de ellas, que no era posible ofrecer ninguna lectura de su inscripción. Sin embargo, existe lectura y traducción de ambas lápidas realizada por Pascual de Gayangos y publicadas por A. Delgado y Hernández, "Bosquejo histórico de Niebla", Boletín de la Real Academia de la Historia, XVIII (1891), 484-550, especialmente 516-518.

2 Como los apígrafes encontrados en el Castillo del Cuerno, en Fuentes de León, uno de ellos funerario 
dra se ha preparado y alisado para recibir el epígrafe y el campo epigráfico estaba delimitado por filetes tallados, como se puede ver en el segundo fragmento, pues conserva restos del arranque del filete en el lateral derecho.

\section{LECTURA Y TRADUCCIÓN DEL FRAGMENTO $\mathrm{N}^{\mathrm{0}} 1$ :}

Es un pequeño fragmento de forma irregular que conserva restos de dos renglones de escritura (figura 2). Sus medidas son: $7,8 \mathrm{~cm}$ de ancho y 11,0 $\mathrm{cm}$ de alto.

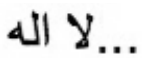 ....[الهاله}

...No hay divinidad

salvo Dios....

En cuanto a sus rasgos gráficos, hay que destacar los remates foliados en las astas de los grafemas, con la particularidad de que presentan la misma orientación hacia la izquierda en el alif y el $l \bar{a} m$ consecutivos del término ilāh, mientras que lo habitual es que el remate del alif se oriente a la derecha y el del $l \bar{a} m$ hacia la izquierda. Este mismo hecho gráfico se ha podido constatar en una estela funeraria de Beas de Segura (Jaén), con el epitafio de un varón fallecido en el año 457/1065, realizado en cúfico inciso ${ }^{3}$, que presenta todos los apéndices de las astas orientados hacia la izquierda, y en una pequeña pieza de metal, una matriz de sello en bronce dorado, al que se ha otorgado una cronología entre los siglos XI-XII, procedente de la necrópolis islámica de Mértola (Portugal), aunque no está directamente relacionado con el contexto funerario, y que presenta una inscripción en negativo realizada en cúfico con todos los ápices de las astas orientados a la derecha (cuando se restituye el texto en positivo $)^{4}$. También en el epígrafe en cúfico florido

del siglo XI y otros dos no funerarios, de cronología almohade; $\mathrm{M}^{\mathrm{a}}$ A. Martinez Núñez, Epigrafía árabe del Museo Arqueológico Provincial de Badajoz. Junta de Extremadura, Badajoz, 2013, nº 4, 7 y 8.

3 E. Lévi-Provençal, Inscriptions arabes d'Espagne, Leiden-París, 1931, no 154; A. Labarta, "Las lápidas árabes de la provincia de Jaén", en Homenaje a Manuel Ocaña Jiménez, Córdoba, 1990, $\mathrm{n}^{\mathrm{Q}}$ 15, 132.

4 S. Gilotte, D. Le Bars, y $\mathrm{M}^{\mathrm{a}}$ A. Martínez Núñez, "Matriz de sinete", Os signos do quotidiano. Gestos marcas e símbolos no al-Ândalus, Catálogo da exposição. Campo arqueológico de Mértola, 2011, 54-55. El epígrafe del sello reproduce un antropónimo, como suele ser habitual

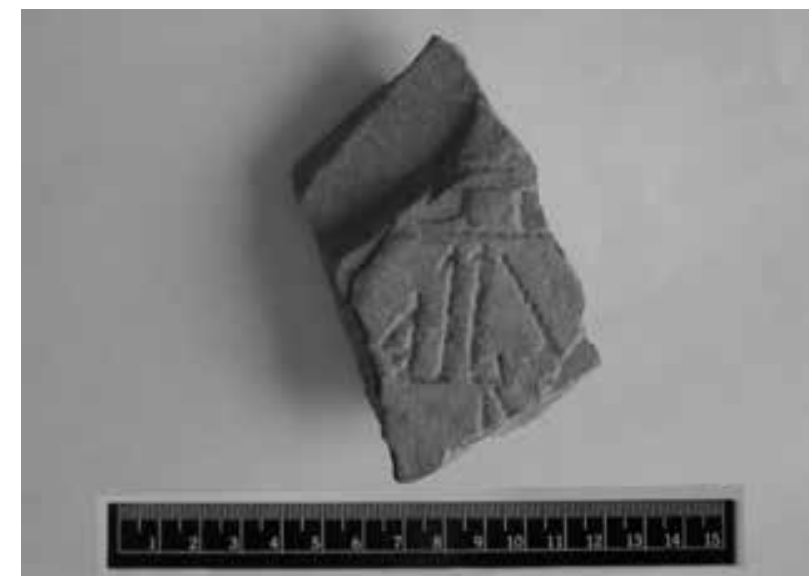

Fig. 2. Fragmento epigráfico $n^{\circ} 1$.

que ostenta una basa de columna almeriense, que debe ser datada en el siglo XI, se observa que todos los apéndices florales, aplicados a varios grafemas, aunque no a la secuencia alif lām ni al nexo $l \bar{a} m$ alif, se orientan hacia la derecha ${ }^{5}$.

Asimismo, hay que destacar la forma que adopta el $h \bar{a}$ 'final, con factura cuidada y forma de triángulo rematado por un pequeño apéndice perpendicular en la parte superior. Esta forma se detecta ya desde mediados del siglo $\mathrm{X}$, como podemos ver en varios ejemplares de la provincia de Jaén: una lápida conmemorativa de la construcción de una mezquita en el 333/944-45, hallada en Bélmez de la Morale$\mathrm{da}^{6} \mathrm{y}$ en una estela funeraria procedente de Baños de la Encina, de finales del siglo X (figura 3), con el epitafio de un varón en cúfico inciso ${ }^{7}$, pero también es la que de manera habitual se presenta en epígrafes realizados en cúfico inciso del siglo XII y de los siglos siguientes, como en el epitafio de Arjona, del $549 / 1154^{8}$, o en la inscripción hallada en Fuentes

en este tipo de objetos; cfr. M $\mathrm{M}^{\mathrm{a}}$ A. Martínez Núñez (con la colaboración de I. Rodríguez Casanova y A. Canto García), Epigrafía árabe, Catálogo del Gabinete de Antigüedades. Real Academia de la Historia, Madrid, 2007, 329-330.

5 J. Lirola Delgado; "Inscripciones árabes inéditas en el Museo Provincial de Almería”, Al-Qantara, XXI, 1 (2000), $\mathrm{n}^{\circ} 3,110-111$. El texto reproduce un fragmento del Corán (II, 85), por lo que puede proceder de la mezquita mayor de Almería, como apunta Jorge Lirola. Por su rasgos gráficos, debe corresponder a la ampliación acometida por Jayrān a comienzos del siglo V/XI.

6 Labarta, "Las lápidas árabes de la provincia de Jaén”, $\mathrm{n}^{0} 3,127$

7 Martínez Núñez, Epigrafía árabe, Catálogo del Gabinete de Antigüedades, $\mathrm{n}^{0} 57,58-59$.

$8 \mathrm{Su}$ copia en yeso se conserva en el Museo Arqueológico Nacional de Madrid; Lévi-Provençal, Inscriptions arabes d'Espagne, $\mathrm{n}^{0} 156$, lám. XXXIIIc; Labarta, "Las lápidas 


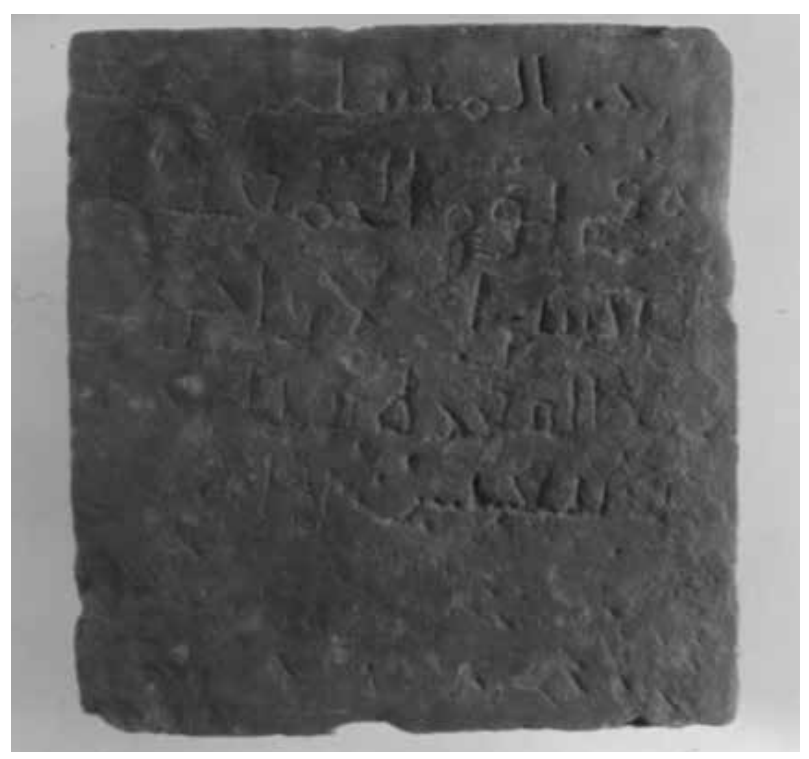

Fig. 3. Inscripción funeraria de Baños de la Encina Jaén). Finales del siglo IV /X.

de león (Badajoz) ${ }^{9}$, de cronología almohade, aunque estas dos inscripciones tienen la particularidad de tener anotados los puntos diacríticos.

También es destacable el retroceso a la derecha, sobre la misma línea de escritura y con apéndice oblicuo al renglón, del grafema alif aislado. Este rasgo gráfico es propio del cúfico tallado en relieve, no del realizado en labra incisa, durante siglo XII y especialmente en el periodo almohade ${ }^{10} \mathrm{y}$ a partir de él, y viene a mostrar el diseño especial y la factura muy cuidada del cúfico inciso de esta lápida.

Por lo que respecta al contenido, se ha conservado fragmentariamente la fórmula del tahlīl, sobre la unidad de Dios, que es la primera parte de la šahāda o profesión de fe musulmana. La profesión de fe se incluye habitualmente en los epitafios andalusíes de todas las épocas y suele aparecer después de la mención del nombre del difunto, tras la expresión wa-huwa yašhadu ("testimoniando") o wa-kana yašhadu ("y daba testimonio"), pero

árabes de la provincia de Jaén”, n $17,133-134$.

9 Martínez Núñez, Epigrafía árabe del Museo Arqueológico Provincial de Badajoz, $\mathrm{n}^{0}$ 8, 11-12

10 M. Acién Almansa y $\mathrm{M}^{\mathrm{a}} \mathrm{A}$. Martínez Núñez, Inscripciones árabes del Museo de Málaga, Madrid, 1982, nº 16, lám. XVI, 33 y nº 20, lám. XXV, 37; Mª A. Martínez Núñez, "Epigrafía y propaganda almohades", $A l$ Qanțara, XVIII, 2 (1997), 430, figs. 1 y 2; Martínez Núñez, Epigrafía árabe del Museo Arqueológico Provincial de Badajoz, $\mathrm{n}^{\circ}$ 9, 12, 21-22 y n 12, 25-26; Portugal islâmico. Os últimos sinais do Mediterrâneo, Catálogo exposição, Lisboa, 1998, nº 296 y 303, 243 y 247.

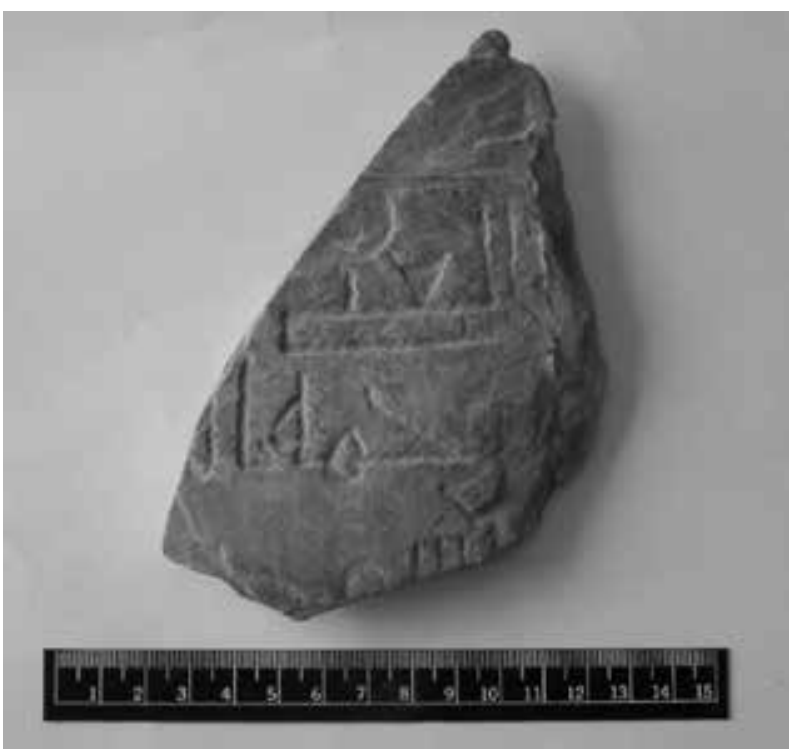

Fig. 4. Fragmento epigráfico $\mathrm{n}^{\circ} 2$.

puede ubicarse también antes del nombre del difunto, tras la basmala introductoria, por lo general formando parte de alguna aleya coránica referida a la šah $\bar{a} d a^{11}$.

\section{LECTURA Y TRADUCCIÓN DEL FRAGMENTO $\mathrm{N}^{\mathrm{Q}} 2$ :}

Es un fragmento de tamaño algo mayor que el precedente, de forma triangular, que conserva restos de tres renglones de escritura, así como del filete de enmarque en el lateral derecho (figura 4). Sus medidas son: $9,9 \mathrm{~cm}$ de ancho y $13,3 \mathrm{~cm}$ de alto.

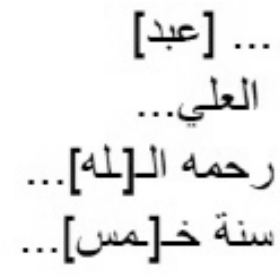

$\ldots$. Abd
$a l-{ }^{c} A l \bar{l} . .$.

Dios tenga misericordia de él ...

en el año cinco...

11 C. Barceló, "Estructura textual de los epitafios andalusíes", en Homenaje a Manuel Ocaña, Córdoba, 1990, 44-46; de la misma autora, La escritura árabe en el país valenciano, Valencia, 1998, vol. 1, 84; Mª A. Martínez Núñez, "Estelas funerarias de cronología califal aparecidas en Orihuela (Alicante)", Al-Qanțara, XXII, 1(2001), 51,54, $57,67,71-72$. 


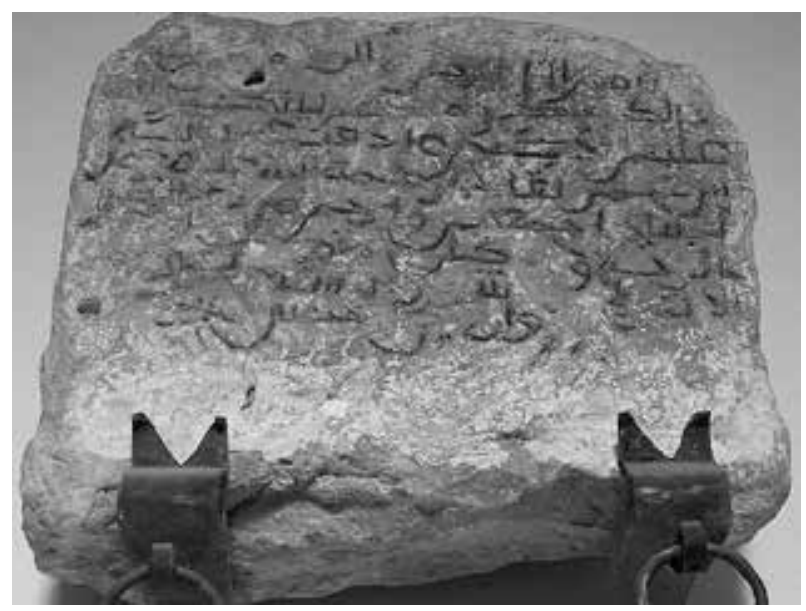

Fig. 5. Inscripción funeraria de Arjona (Jaén) con fecha expresa del año 549/1154.

En este segundo fragmento hay que destacar como rasgo gráfico más específico el exorno en forma de hilāl ("cuarto creciente") que remata el lām medial, en el nombre al- ${ }^{c} A l \bar{\imath}$ (renglón primero), y que ha obligado a acortar la altura del asta. La forma que adopta el $h \bar{a}$ 'final y el retroceso en escuadra a la derecha, sobre la misma línea de escritura y con apéndice oblicuo al renglón, del grafema alif en el inicio del término Allāh (segundo renglón), son idénticos a los que presenta el primer fragmento.

La factura del grafema 'ayn en posición medial, cerrado arriba y en forma de un triángulo invertido, es también un rasgo frecuente en los epígrafes en cúfico inciso de los siglos XII y XIII, como se observa en el funerario de Arjona (figura 5), antes mencionado, y en la inscripción conmemorativa de la fundación de un alminar, hallada en Porcuna, también en Jaén, del año 660/1262 ${ }^{12}$, aunque asimismo se documenta puntualmente en inscripciones de cronología anterior ${ }^{13}$.

El texto de este segundo fragmento reproduce la onomástica del difunto, del que se nos ha conservado sólo la segunda parte de un ism, el teóforo 'Abd $a l-{ }^{c} A l \bar{\imath}$ ("Servidor/Esclavo del Altísimo"), que se ha podido documentar también en un epitafio pacense

12 Labarta, "Las lápidas árabes de la provincia de Jaén", $\mathrm{n}^{\circ} 20,35-137$.

13 Con esta forma cerrada arriba, junto al diseño abierto, se realiza en epígrafes en cúfico inciso de finales del siglo X, como el de Baños de la Encina (fig.2), antes citado (Martínez Núñez, Epigrafía árabe, Catálogo del Gabinete de Antigüedades, $\mathrm{n}^{\circ}$ 57), y en los datados en la centuria siguiente, como los procedentes de territorios del Garb alAndalus, en el actual Portugal; Portugal islâmico, $\mathrm{n}^{\mathrm{Q}} 288$, 289 y $290,238-240$.

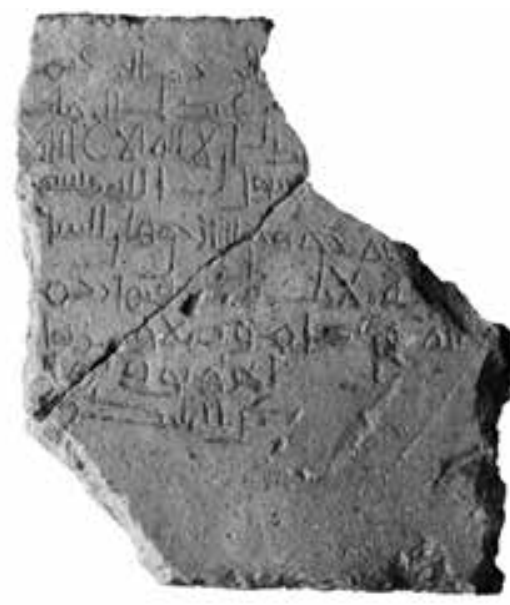

Fig. 6. Ladrillo funerario de cronología almohade. Fuente del Maestre (Badajoz).

de cronología almohade ${ }^{14}$, realizado en cúfico inciso sobre una estela de cerámica (figura 6). Este ism se ubicaría con bastante probabilidad tras la expresión $h \bar{a} \underline{d} \bar{a}$ qabr ("este es el sepulcro de"), como sucede en el otro epitafio que fue hallado en el siglo XIX en el término de Puebla de Guzmán ${ }^{15}$, o tras el verbo tuwuffiya ("murió"), como suele consignarse en los textos funerarios de zonas rurales ${ }^{16}$, $y$ es posible que fuese acompañado de algún otro elemento de la cadena onomástica, probablemente un nasab, pues es el que se consigna con mayor frecuencia en epigrafía funeraria andalusí, aunque en el ejemplar almohade en cerámica de Badajoz, más arriba citado, sólo se consigna el ism ${ }^{17}$.

La mención del difunto va seguida de la expresión rahima-hu Allāh ("que Dios tenga misericordia de él”), una invocación a favor del fallecido que es fórmula de inclusión casi permanente en los epitafios andalusíes, aunque a veces se presente con variantes,

14 Martínez Núñez, Epigrafía árabe del Museo Arqueológico Provincial de Badajoz, $\mathrm{n}^{\mathrm{0}}$ 10, 22-23. Este ladrillo funerario procede de Fuente del Maestre (Badajoz) y es un caso único en epigrafía funeraria andalusí, por reproducir, entre las fórmulas de salida, el deber de hisba, en su formulación coránica al-amr bi-l-macrūf wa-lnahy ${ }^{c}$ an al-munkar ("ordenar lo establecido y prohibir lo reprobable"), el pilar de la doctrina y actuación del Mahdī Ibn Tūmart.

15 Véase más arriba la nota 2.

16 Barceló, "Estructura textual de los epitafios andalusíes", 45-46; M $M^{a}$ A. Martínez Núñez, "Epigrafía funeraria en al-Andalus (siglos IX-XII)", Mélanges de la Casa de Velázquez, Nouvelle série, 41, 1 (2011), 181-209, 188.

17 Y lo hace de forma abreviada, pues lo que se ha labrado es: ${ }^{c} A b d$ al- ${ }^{c} A$, عبد. 


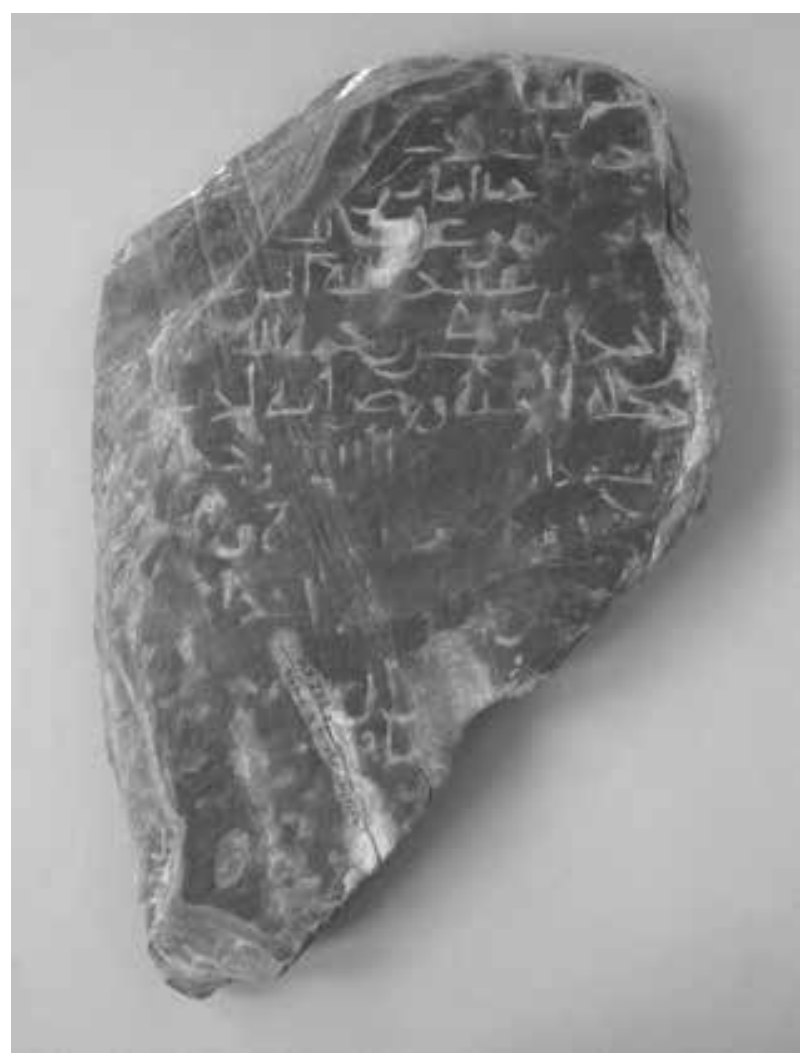

Fig. 7. Lápida funeraria en pizarra hallada en Puebla de Guzmán. Siglo XII.

la más frecuente raḥmat Allāh calay-hi/hā ("la misericordia de Dios sea sobre él/ella"), y ampliada con la inclusión de otras fórmulas. Según las épocas y lugares, esta eulogia puede consignarse tras el nombre del difunto o tras el verbo tuwuffiya ("murió") 18 .

En el último renglón de los conservados, se consigna parte de la fecha del óbito. En los epitafios andalusíes la datación es bastante completa, pues se suele especificar el momento de la muerte, la feria de la semana, el día del mes y el año ${ }^{19}$. En este caso sólo se nos ha conservado el inicio del año, con el primer grafema del nombre de unidad jams ("cinco"), por lo que no se puede restituir ningún otro elemento de la fecha consignada.

Por los escasos restos conservados no se puede conocer la tipología exacta de la lápida, sólo que sería una estela tabular, con el campo epigráfico

18 Barceló, "Estructura textual de los epitafios andalusíes", 47; Barceló, La escritura árabe en el país valenciano, 80; Martínez Núñez, "Estelas funerarias de cronología califal aparecidas en Orihuela", 59-60.

19 Lévi-Provençal, Inscriptions arabes d'Espagne, XXII, nota 1; Martínez Núñez, "Estelas funerarias de cronología califal aparecidas en Orihuela", 60. enmarcado por filetes tallados. Este tipo de estelas, que presenta variantes según las épocas y las zonas de procedencia ${ }^{20}$, podían ir hincadas a la cabecera de la sepultura, las que presentan en la parte inferior un espacio sin epigrafiar, o podían ubicarse adosadas a un murete o pared de alguna estructura funeraria construida al efecto, como se constata en el caso de una estela funeraria del siglo $\mathrm{X}$ hallada en Orihuela (Alicante) ${ }^{21}$ y en el del epitafio del tesorero y $q \bar{a} \dddot{i} d$ del califa al-Nāṣir procedente de la Suda de Tortosa $^{22}$. La reutilización de estos fragmentos en la construcción de los muros del Castillo tampoco permite saber nada de su ubicación original.

A pesar de que el tipo de grafía utilizado en los dos fragmentos es el cúfico inciso, se presenta con una factura muy cuidada y una apariencia bastante evolucionada, sin rasgos arcaizantes, cuyos paralelos andalusíes datan en su mayor parte del siglo XII. A falta de contar con una fecha expresa, estas características inducen, pues, a otorgarles una cronología no anterior al siglo XII y con mucha más probabilidad a datarlos en el siglo almohade, entre la segunda mitad del XII y primera del XIII. Esta propuesta atribución cronológica concuerda con la que hay que adjudicar a la otra estela de pizarra hallada también en el Cerro del Águila, en Puebla de Guzmán (figura 7), con el epitafio de un varón realizado en cúfico inciso. Aunque se le ha otorgado una cronología de siglo $\mathrm{X}^{23}$, sus características gráficas remiten a una fecha más tardía ${ }^{24}$. Así, su grafía

20 Lévi-Provençal, Inscriptions arabes d'Espagne, XXIII-XV; M. Ocaña Jiménez, "Historia y epigrafía en la Almería islámica”, en Homenaje al Padre Tapia. Almería en la historia. I Encuentro de Cultura Mediterránea (Almería, 27 al 31 de octubre 1986), Almería, 1988, 148 y ss. y 182; Ma A. Martínez Núñez, "La estela funeraria en el mundo andalusí", Actas del V Congreso Internacional de Estelas Funerarias, Soria, 1994, 421-424; Barceló, La escritura árabe en el país valenciano, 62-71.

21 Martínez Núñez, "Estelas funerarias de cronología califal aparecidas en Orihuela”, $\mathrm{n}^{\circ} 2,46,74$.

22 P. Yzquierdo, "Lápida funeraria del governador ${ }^{\mathrm{c}} \mathrm{Abd}$ al-Salām b. 'Ábd Allāh b. Basīl», en L'Islam i Catalunya. Catàleg, Barcelona, 1998, n. '24, 48-49.

23 Oliva, Gálvez y Valencia, "Fondos epigráficos del Museo Arqueológico de Sevilla”, 455.

24 De hecho Carmen Barceló le otorgó a esta lápida una cronología del siglo VI/XII; C. Barceló, "Los escritos árabes de la rābita de Guardamar”, en R. Azuar Ruiz (coord.), Fouilles de la Rábita de Guardamar I. El ribāt califal: excavaciones y estudios (1984-1992), Madrid, 2004, 141, nota 29. 
cúfica, aunque bastante menos cuidada en su ejecución, es muy semejante a la analizada en los dos fragmentos anteriores, como se puede ver claramente en los renglones $5^{\circ}$ a $7^{\circ}$, los mejor conservados. Hay que destacar especialmente la forma que adopta el mìm final de la basmala, en el inicio del renglón $1^{\circ}$, con un apéndice por debajo de la línea de escritura que se prolonga en su parte final hacia la izquierda. Este rasgo gráfico, más propio de la escritura cursiva y utilitaria que de la cúfica, tiene en esta lápida de Puebla de Guzmán un diseño diferente y más evolucionado que el que presenta en el fragmento de pizarra hallado en el castillo del Cuerno (Badajoz) ${ }^{25}$, con fecha expresa del año 483/1091 (figura 8), o el que se puede observar en una de las inscripciones en cúfico inciso de la rābița de Guardamar ${ }^{26}$. Sin embargo, es prácticamente idéntico al de los epígrafes del siglo XII realizados en cúfico inciso de la provincia de Jaén, como el de Arjona del año $549 / 1154^{27}$, el hallado en el Castillo de Baños Encina (figura 9) ${ }^{28}$, datado entre los siglos XII-XIII, o el procedente de Porcuna, que conmemora la construcción de un alminar en el año 660/1262 29. $Y$ es que en época almohade este diseño del $m i ̄ m$ final no solo está presente en epígrafes realizados en cúfico inciso, sino que empieza a usarse en las inscripciones en cúfico tallado en relieve. Así, este grafema se presenta con apéndice por debajo de la línea de escritura y prolongación hacia la izquierda en las inscripciones de las grandes puertas de aparato de Marrakech y de Rabat ${ }^{30}$, por tanto en el cúfico usado en fundaciones soberanas de los califas mu'miníes, y ese mismo rasgo se encuentra en inscripciones funerarias en cúfico

25 Martínez Núñez, Epigrafía árabe del Museo Arqueológico Provincial de Badajoz, $\mathrm{n}^{\circ}$ 4, 7. Este mismo diseño en el mīm de la basmala se observa en la lápida en cúfico inciso de Noudar (Portugal), también de finales del siglo XI; Portugal islâmico, $\mathrm{n}^{\mathrm{O}} 288,238$.

26 Barceló, "Los escritos árabes de la rābița de Guardamar”, 139, fig. 61 B. Puede que este epígrafe sea el más antiguo en presentar esta particularidad gráfica.

27 Lévi- Provençal, Inscripctions árabes d'Espagne, $\mathrm{n}^{\mathrm{Q}} 156$, lám. XXXIIIc.

28 Martínez Núñez, "Epigrafía funeraria en al-Andalus (siglos IX-XII)", 193-194, fig. 6.

29 Labarta, "Las lápidas árabes de la provincia de Jaén", $\mathrm{n}^{\mathrm{o}} 20,135$ y $136-137$.

30 Martínez Núñez, "Epigrafía y propaganda almohades”, 430, lám. 3, fig. 2, donde se reproduce un dibujo con el detalle del cúfico usado en las bandas del alfiz de la Bāb al-Ruwāh de Rabat.

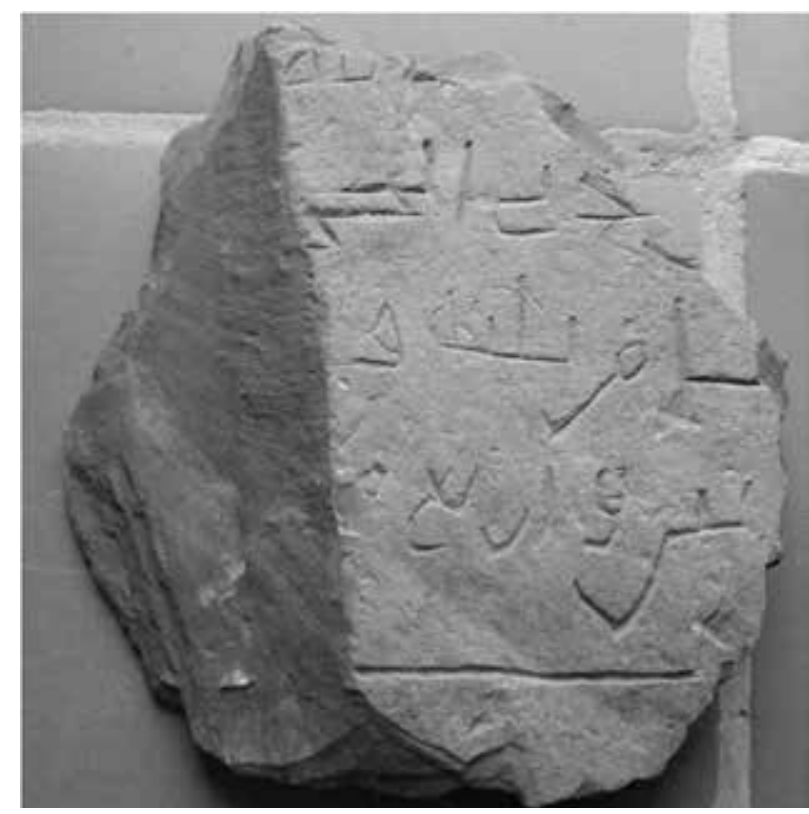

Fig. 8: Fragmento de lápida funeraria en pizarra con fecha expresa del 484/1091. Castillo del Cuerno (Fuentes de León, Badajoz).

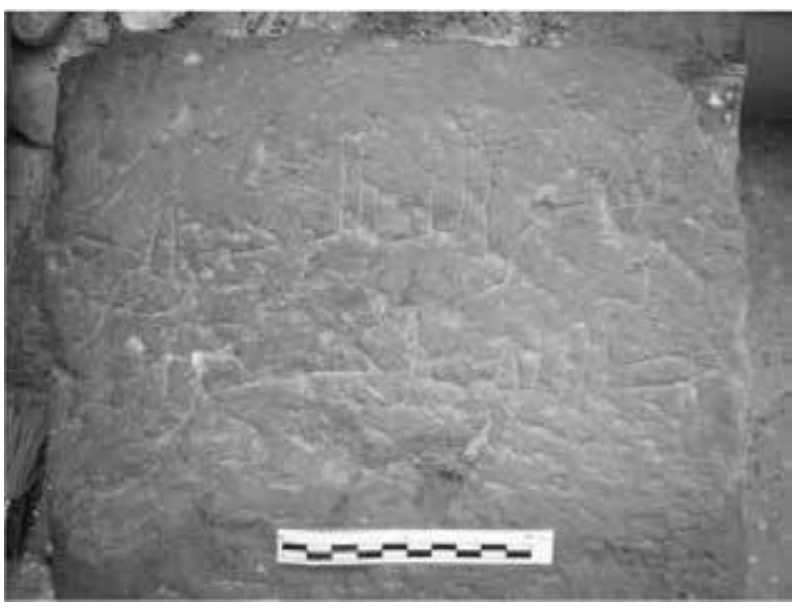

Fig. 9: Lápida funeraria de cronología almohade. Castillo de Baños de la Encina (Jaén).

tallado en relieve de cronología almohade, como en la mqābriyya malagueña del año $618 / 1221^{31} \mathrm{y}$ en algunos ejemplares de Portuga ${ }^{32}$. Alguna incidencia hubo de tener en este hecho la generalización del uso de la grafía cursiva en la epigrafía almohade, y la decisión de realizar en dicha modalidad gráfica inscripciones emblemáticas de la dinastía, como las que discurren por los $m i h r a \bar{b} b / \mathrm{s}$

31 Martínez Núñez, "Epigrafía y propaganda almohades”, 424, lám. 1, fig.1.

32 Portugal islámico: $\mathrm{n}^{0} 303,247$ y nº 304, 248-249. 
de la Kutubiyya y de la mezquita de la Qaṣba, ambos en Marrakech ${ }^{33}$.

La constatación de esas semejanzas con ejemplares de distintos enclaves del garb al-Andalus ${ }^{34}$, y con los de otras zonas de la Península, viene a corroborar la existencia de rasgos gráficos comunes en cada etapa o periodo de la epigrafía andalusí, a pesar de que también existen, sin duda alguna, particularismos locales; unos rasgos comunes que a veces pueden responder a las modalidades gráficas introducidas en las inscripciones soberanas a instancias del poder, mientras que en otras ocasiones se producen al margen de esas orientaciones.

Por otra parte, el hecho de haber podido disponer de una reproducción fotográfica de la otra lápida en pizarra de Puebla de Guzmán, que se conserva en el Museo Arqueológico Provincial de Sevilla ( $n^{0}$ de registro REP00268-1 y n⿳0 de inventario general $3377)^{35}$, ha permitido comprobar el mal estado original de la pizarra, lo que sumado a unas inadecuadas condiciones de conservación, han ocasionado la pérdida actual de parte del texto de la inscripción, especialmente en su mitad inferior, pero también han posibilitado revisar y plantear alguna variación en la lectura de la parte inicial y de la onomástica del difunto, que se ofrece a continuación.

Lectura del epígrafe conservado en el Museo Arqueológico de Sevilla:

33 Martínez Núñez, "Epigrafía y propaganda almohades", 421-422; Mª A. Martínez Núñez, "Ideología y epigrafía almohades”, en P. Cressier; M. Fierro; L. Molina (eds.), Los almohades: problemas y perspectivas, Madrid, 2005, vol I, 8-9.

34 Sobre los territorios que forman parte del Occidente de al-Andalus; A. García Sanjuán, "La caracterización geográfica del Garb al-Andalus en las fuentes medievales”, Medievalista (en línea), nº 6 (julio 2009), 8-13 (consultado 03704/2014). Disponible en:

www.2fcsh.pt/iem/medievalista/

35 La fotografía que se reproduce en este artículo, tras solicitar y obtener la autorización pertinente, es propiedad del Museo Arqueológico Provincial de Sevilla, a cuya Directora, Dña. Ana Navarro Ortega, quiero agradecer sinceramente su rápida respuesta, buena disposición y colaboración, así como a la Jefa del Departamento de Conservación e Investigación del Museo, Doña Concepción San Martín Montilla.

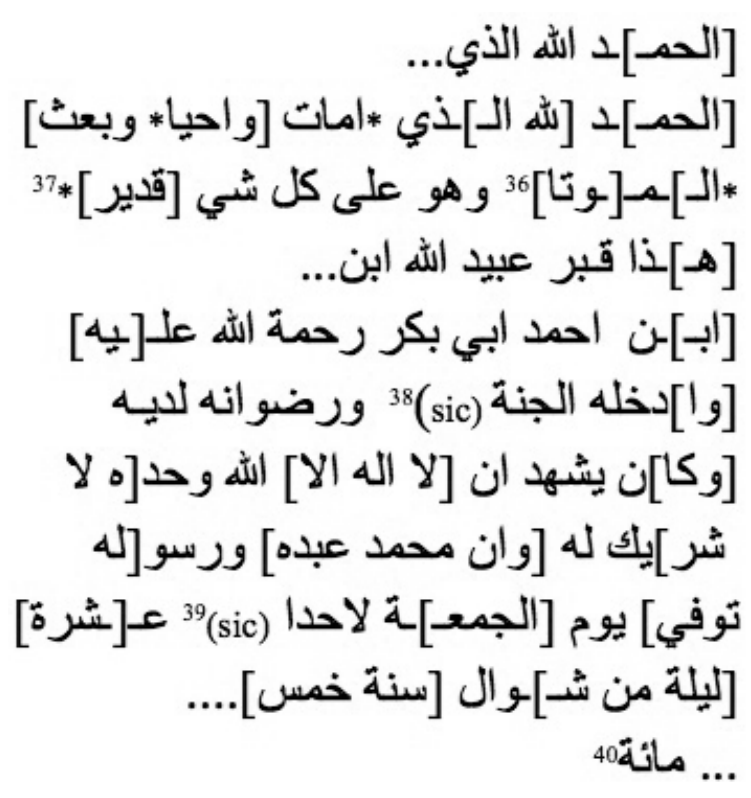

En el nombre de Dios, el Clemente, el Misericordioso.

La alabanza a Dios que...

La alabanza a Dios que* da la vida y da la muerte* (Q. LIII, 44) y resucita

*a los muertos, pues Él es poderoso sobre todas las cosas* (Q. XLII, 9) ${ }^{41}$.

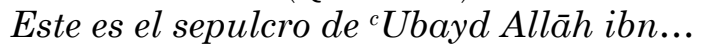
ibn Ahmad Abi Bakr, que la misericordia de Dios sea sobre él,

lo introduzca en el paraíso, y que sea para él

36 Este término ha perdido en la actualidad su parte final, pero esta es la lectura que ofrecieron Oliva, Gálvez y Valencia en su momento y en la que se había sustituido el alif maqșūra de al-mawtà por alif vertical, un hecho bastante habitual en epigrafía andalusí.

$37 \mathrm{El}$ texto incluido entre asteriscos corresponde a citas textuales coránicas.

38 Hay una incongruencia sintáctica en esta segunda eulogia, pues se sobreentiende que el término Allāh es el sujeto de la oración y no se especifica porque ya ha aparecido en la frase anterior, pero en esta no hace oficio de sujeto sino de segundo término de una idāfa.

39 Por احدى

40 En la lectura de Pascual de Gayangos se incluye el grafema final del nombre de unidad de la centena, un $\sin$, que aún se podría leer en ese momento, por lo que la centena sería jams mīa, "quinientos"; es decir, siglo VI/XII, lo que viene a corroborar la cronología propuesta para esta lápida.

41 Lo incluido entre asteriscos es lo que textualmente se expresa en estos dos pasajes coránicos, pero las frases completas son: wa-anna-hu huwa amāta wa-ahyā (Q. LIII, 44 completa) y ...wa-huwa yuhyī al-mawtà wa-huwa 'alà kull šay' qadīr (parte final de Q. XLII, 9). 
Su gracia ${ }^{42}$.

Y daba testimonio de que no hay más

divinidad que Dios, Él solo, no

tiene asociado, y de que Muhammad es Su

siervo y Su enviado.

Murió el viernes, once...

de šawāl del año cinco....

...cien...

Así pues, el Cerro del Águila ha proporcionado una inscripción virtualmente completa $\mathrm{y}$ dos fragmentos de otra. Ambas son funerarias y probablemente de cronología almohade, aunque sólo la que se encuentra en el Museo de Sevilla ha conservado la onomástica del difunto, que es nombrado por su ism, 'Ubayd Allāh, un doble $n a s a b$, aunque el primero de ellos ha desaparecido parcialmente, y por una kunya, Abū Bakr; un desconocido, pero cuya cadena onomástica indica su probable abolengo árabe. Sin embargo, la sola mención de la kunya Abū Bakr, muy usual en el mundo islámico en general y en al-Andalus en particular, no basta para identificar al difunto con un miembro de los Bakríes, los que fueron soberanos independientes de la taifa de Huelva a partir del 403/1012-1013 ${ }^{43}$. La caligrafía cuidada de estos epígrafes y su contenido, que concuerda con el de epitafios de cementerios urbanos, inducen a pensar que pudieron ser realizados en algún taller de cierta relevancia de una de las poblaciones del garb al-Andalus, zona a la que pertenece el lugar de la Peña del Águila.

En este sitio, como se ha adelantado, se encuentra el despoblado medieval de Alfayat de la Peña, un topónimo que aparece recogido por primera vez en uno de los itinerarios de la conquista portuguesa de las tierras del suroeste de al-Andalus, el protagonizado por parte del rey portugués Sancho II Capelo con el auxilio de la Orden de Santiago.

42 Una incongruencia sintáctica parecida en la forma de concatenar las tres eulogias a favor del difunto, que van unidas por la coordinativa $w \bar{a} w$, se puede observar en una estela funeraria de Murcia, con el epitafio de un $q \bar{a} \grave{i} d$ de Ibn Mardanīš (m. 566/1161); Martínez Núñez, Epigrafía árabe. Catálogo del Gabinete de Antigüedades, $\mathrm{n}^{\circ}$ 65, 170-171.

$43 \mathrm{M}^{\mathrm{a}} \mathrm{J}$. Viguera Molins, "Historia política", en $\mathrm{M}^{\mathrm{a}} \mathrm{J}$. Viguera Molins (coord.), Los reinos de taifas. Al-Andalus en el siglo XI, vol. VIII-I Historia de España de Menéndez Pidal, Madrid, 1994, 70.
La grave crisis del imperio almohade permitió un importante avance de las tropas cristianas de la Orden de Santiago, comandadas por Paio Peres Correia, Comendador de Portugal, que desde su base en Alcácer do Sal inició una fase de hostigamiento y conquistas sobre territorio musulmán desde 1228, que culmina en primera instancia con la toma de Aljustrel en 1234. Desde esta fortaleza la embestida portuguesa continuó con entradas de castigo y pillaje sobre Estombar, Alvor y Odemira, hasta terminar con la conquista de Mértola en 1238; enclave este último sobre el Guadiana desde el que la hueste santiaguista cruzó el río y ocupó Alfajar de Penha en 1239, y en 1240 Ayamonte, en cuyo cerco participó el rey Sancho II, y Cacela (Rei, 2003). Los historiadores portugueses identificaron Alfajar de Penha con la localidad de Alájar (Huelva), pero finalmente J. Carlos García consideró que según la documentación medieval portuguesa debería situarse en el término de Puebla de Guzmán ${ }^{44}$.

El mismo lugar reaparece como Alfayat de la Peña en la documentación castellana después de la conquista de Sevilla, en primer lugar en 1253 como uno de los asentamientos del alfoz que se otorga a Sevilla después de su conquista ${ }^{45}$, y posteriormente en la cesión de la tierra de Niebla a Doña Beatriz ${ }^{46} y$ entre los lugares que formaron parte del Concejo de Niebla ${ }^{47}$, por lo que debió pasar a formar parte del término de Niebla después de su conquista en $1262^{48}$. El topónimo fue reducido a Puebla de Guzmán por A. Delgado y Hernández a partir del descubrimiento en sus alrededores de las dos lápidas funerarias ${ }^{49}$, que fueron atribuidas a miembros de la familia de los Bakríes ${ }^{50}$.

44J. Carlos García, "Alfajar de Pena. Reconquista e repovoamento no Andévalo do século XIII", Actas das II Jornadas Luso-Espanholas de Historia Medieval, III, Porto, 1989, 907-925.

45 M. González Jiménez, Diplomatario andaluz de Alfonso X, Sevilla, 1991, doc. 80.

46 R. Amador de los Ríos, Huelva, Barcelona, 1891 (reimpresión, Huelva, 1983), 775; González Jiménez, Diplomatario andaluz, 557-564.

47 M. A. Ladero Quesada, Niebla, de Reino a Condado, Huelva, 1992, 32.

48 A. M $\mathrm{M}^{\mathrm{a}}$ Anasagasti y L. Rodríguez, Niebla en la época de Alfonso $X$, Huelva, 1984.

49 Véase nota 2.

50 Amador de los Ríos, Inscripciones árabes de Sevilla, 108-110; Amador de los Ríos, Huelva, 799-800; Oliva, Gálvez y Valencia, "Fondos epigráficos del Museo de Sevilla, 455-456. 
Sin embargo, las inscripciones aparecieron en el Santuario de la Virgen de la Peña (Puebla de Guzmán), en cuyo entorno se ha ubicado el asentamiento islámico ${ }^{51}$. El asentamiento islámico continuó habitado como lugar de repoblación hasta el siglo XIV, cuando se construyó el Castillo de la Peña del Águila en tiempos del Condado de Niebla ${ }^{52}$. Todos estos pormenores han quedado confirmados por la reciente publicación de la voluminosa documentación sobre Niebla del Archivo Ducal de Medina Sidonia ${ }^{53}$.

Alfayat de la Peña sería cabecera de la tierra de Niebla en la comarca del Andévalo, y se iría despoblando paulatinamente a raíz de la creación en el siglo XIV de un nuevo núcleo de población en la Alquería de Juan Pérez, que acabaría convertida en Puebla de Guzmán en el siglo XV (1445), gracias a una nueva carta puebla otorgada por don Juan de Guzmán, conde de Niebla, a fin de revitalizar demográficamente ese sector de su señorío ${ }^{54}$.

El asentamiento islámico y bajomedieval cristiano fue casi totalmente arrasado para la construcción de una zona de aparcamiento de vehículos para la celebración de la Romería de Nuestra Señora de la Virgen de la Peña. Dado que continuó ocupado en época bajo-medieval, cuando se construyó el Castillo de la Peña del Águila, suponemos que la necrópolis islámica de la que proceden estos epígrafes fue expoliada en esta época y algunas de las lápidas funerarias se reaprovecharon como material de construcción en la fortaleza cristiana.

51 F. Roldán; J.A: Pérez, "Entorno a la ubicación de Alfayat de la Peña”, Homenaje a D. Jacinto Bosch Vilá, I, Granada, 1991, 323-333.

52 Roldán y Pérez, "Entorno a la ubicación de Alfayat de la Peña”.

53 A. M ${ }^{a}$ Anasagasti y L. Rodríguez, Niebla y su tierra en la Baja Edad Media. Historia y Documentos, I, Huelva, 2006, 69-70. Por su situación se ha relacionado con Hayr b. Abī Jālid, una estación intermedia en el itinerario entre Gibraleón y Badajoz; J. A. Pérez Macías, "Poblamiento y explotación en el suroeste de al-Andalus", Paisaje y Naturaleza en Al-Andalus, Granada, 2004, 275; F. Roldán Castro, Niebla musulmana (siglos VIII-XIII), Huelva, 1993, 294.

54 F. Núñez Roldan, La vida rural en un lugar del Señorío de Niebla: La Puebla de Guzmán (Siglos XVI al XVIII), Huelva, 1985. 